\title{
Risk assessment of toxins derived from Bacillus thuringiensis-synergism, efficacy, and selectivity
}

\author{
Christoph Then
}

Received: 12 March 2009 / Accepted: 28 May 2009 / Published online: 26 June 2009

(C) The Author(s) 2009. This article is published with open access at Springerlink.com

\begin{abstract}
Background, aim, and scope This review deals with publications concerning the mode of action of Bt proteins and their potential synergism with extrinsic factors. The aim was to assess the impact of those factors especially regarding selectivity and efficacy of $\mathrm{Bt}$ toxins and to discuss possible gaps in current risk assessment of genetically engineered plants expressing Bt toxins.

Main features The review shows that several extrinsic factors are able to influence the selectivity and efficacy of Bt toxins. The findings are seen as being relevant for risk assessment in Bt plants. This conclusion is derived by discussing current state of knowledge about the mode of action of $\mathrm{Bt}$ proteins, unexpected effects on non-target organism, and the way how modified $\mathrm{Bt}$ toxins are expressed in genetically engineered plants.

Results Several publications have been identified that show that certain factors and synergism can impact efficacy and selectivity of Bt toxins. These extrinsic factors are various and include other Bt toxins or parts from the spore of Bacillus thuringiensis as well as certain enzymes, environmental stress, non-pathogenic microorganisms, and infectious diseases.

Discussion Research on the underlying mechanism of observed synergism might help to explain some of the effects found in non-target organisms. In general, possible synergism of Bt toxins with extrinsic factors can be relevant for risk assessment of genetically engineered Bt plants since
\end{abstract}

Responsible editor: Peter Schröder

C. Then $(\bowtie)$

Scouting Biotechnology,

Frohschammerstr. 14,

80807 Munich, Germany

e-mail: christoph.then@scouting-biotech.de they expose a modified Bt toxin to the environment under various conditions and over a long period of time.

Conclusions Risk assessment of genetically engineered plants should put into question the general assumption of a high selectivity and a linear dose-response relationship in the toxicity of Bt proteins. Both selectivity and efficacy can be influenced by synergism, which can provoke unexpected and undesired effects in non-target organisms.

Perspectives It is suggested that systematic research be promoted on synergism between Bt toxins and potential extrinsic factors that could impact the spectrum of susceptible organisms. This research should become a prerequisite for risk assessment of Bt plants.

Keywords Bt toxin - Extrinsic factors .

Genetically engineered plants · Non-target organism .

Risk assessment $\cdot$ Synergism $\cdot$ Toxicity

\section{Background, aim, and scope}

So-called Bt plants are one of the dominant genetically engineered crops grown on a large scale and in many regions of the world (ISAAA 2009). There is a wide range of issues being discussed in the context of the risk assessment of these Bt plants. This review deals with specific aspects of risk assessment of the insecticidal $\mathrm{Bt}$ toxins, which are produced in the genetically engineered plants. It is important to understand its mode of action and possible interference with elements from its environment, to be sure that the Bt plants and their toxins do not show unexpected or even hazardous effects under changing environmental conditions. This is especially relevant since Bt Plants are being grown under various regional and climatic conditions; the Bt toxins are produced throughout 
the growing season and get in contact with the environment above and below the ground as well as being used in feed and food. This issue was elaborated by a review of the current literature; in addition, a questionnaire was developed for consulting experts to improve the coverage. To identify contributions that might be difficult to access otherwise, it was agreed (with the experts) to keep their input anonymous.

One crucial issue identified is that published scientific literature not only shows some open questions concerning the general mode of action of $\mathrm{Bt}$ toxins (Gilliland et al. 2002; Crickmore 2005; Hilbeck and Schmidt 2006) but also gives some indications that the toxicity of Bt toxins is influenced by several factors. On the one hand, it is known that, in general, the toxicity of Bt toxins in target organisms depends on factors such as certain $\mathrm{pH}$, proteases, and receptors (Oppert 1999; de Maagd et al. 2001). On the other hand and more specifically, extrinsic factors and specific cofactors can also influence the efficacy of Bt toxins in resistant target organisms and/or might also impact on selectivity and toxicity in non-target organisms (see for example Schnepf et al. 1998; Sharma et al. 2004). While the issue of efficacy of Bt toxins in resistant target organisms is also of economical relevance and quite well investigated by several authors, the potential change of toxicity for nontarget organisms so far is hardly reflected in literature. The aim of this review was to identify publications dealing with relevant factors and their synergisms with Bt toxins and to discuss their specific relevance for risk assessment in genetically engineered plants.

\section{Main features}

Published literature shows that a broad range of extrinsic factors are able to influence the selectivity and/or efficacy of Bt toxins. Some authors even see factors such as gut bacteria as a necessary precondition for toxicity in target organisms (Broderick et al. 2006). Several publications deal with the question how synergism or technological modifications can be used to overcome emergent resistance or make Bt toxins more efficient with target organisms (Dubois and Dean 1995; Lee et al. 1996; Liu et al. 1998; Soberon et al. 2007). These publications should lead to a discussion of whether some factors also can influence resistance to $\mathrm{Bt}$ toxins in non-target organisms. It is interesting that, for example, the Cry1 $\mathrm{Ab}$ protein produced in genetically engineered plants is already modified in a way that could influence its selectivity, being partially processed and activated by plant enzymes (Li et al. 2007). This modification of the protein, caused by technical processing of the DNA (Hilbeck and Schmidt 2006) and additionally influenced by plant enzymes acting as cofactors ( $\mathrm{Li}$ et al. 2007), might help to explain some unexpected effects seen in non-target organisms (Schmidt et al. 2008; Hilbeck et al. 1998; Bøhn et al. 2008; RosiMarshall et al. 2007; Ramirez-Romero et al. 2008). For example, Thomas and Ellar (1983) show that solubilizing of certain Bt proteins (derived from Bacillus thuringiensis var israelensis) can change their toxicity on mammals. Besides enzymatic processing, there are several other factors that can influence the toxicity and selectivity of $\mathrm{Bt}$ proteins, such as a combination of biotic and abiotic stress factors (Koppenhöfer and Kaya 1997; Kramarz et al. 2007), infectious diseases (Dubois and Dean 1995), normal gut bacteria (Broderick et al. 2006 and 2009), interactivity with other Bt toxins and/or the spore part of the toxins (Lee et al. 1996; Liu et al. 1998; Perez et al. 2005; Schnepf et al. 1998; Sharma et al. 2004). These findings make evident the relevance of these effects for ecological risk assessment of Bt crops. In this context, it also should be reflected that the current theory, which explains toxicity of $\mathrm{Bt}$ toxins such as $\mathrm{Cry} 1 \mathrm{Ab}$ in target organisms (de Maagd et al. 2001), leaves room for several open questions (Crickmore 2005; Gilliland et al. 2002) and even contradicting explanations (Zhang et al. 2005, 2006; Broderick et al. 2006; Soberon et al. 2007). In general, it seems premature to rely on the assumed selectivity and a linear dose-response relationship as suggested by Monsanto (2007). On the contrary, the issue of synergism, efficacy, and selectivity remains a gap in current risk assessment.

\section{Results}

B. thuringiensis belongs to the Bacillus cereus group, which contains Bacillus cereus, B. thuringiensis, Bacillus anthracis, Bacillus mycoides, and others (Pigott and Ellar 2007). Toxins of the Cry classification belong to a group of extremely potent toxins that can provoke lesions in the cell membrane; the resulting cell death can be caused by several mechanisms (Tilley and Saibil 2006). Risk assessment of Bt crops is largely based on the evidence that, in target organisms, specific receptors are needed to enable the toxicity of Bt toxins (see for example Schnepf et al. 1998; de Maagd et al. 2001; Monsanto 2007). These specific receptors observed in target organisms are seen as reason to expect toxicity of $\mathrm{Bt}$ toxins only in specific group of species. However, apparently, some quite important gaps in understanding the general mode of action of $\mathrm{Bt}$ toxins are still existing. There are several theories explaining the mode of action of Bt toxins in target organisms, some of them contradictory to one another, for example, Zhang et al. (2005) and Soberon et al. (2007). For Cry1 Ab, Zhang et al. 
(2005) consider a cascade in metabolism being responsible for the toxicity of the Cryl $\mathrm{Ab}$, with the cadherin receptor being important just for binding the protein and starting the cascade. Soberon et al. (2007) object to these findings and explain that the cadherin receptor alone is sufficient to allow the toxins to exert their cytocidal activity of Cry1Ab. Broderick et al. (2006) might comply with the findings of Soberon et al. (2007) but suggests that, in any case, additional bacterial activity is necessary to accomplish the mission of the Cry1 Ab toxin. JimenezJuarez et al. (2007) are discussing different explanatory models and conclude: "Although Bt Cry toxins are widely used as insecticides their mode of action is still not completely understood."

There are several contradictions between the models as currently discussed, but they all reaffirm the assumption that specific receptors are needed for the Bt toxins to show its effects. Pigott and Ellar (2007) are comparing different models used for explaining the mode of action of Cry toxins and identify six different types of receptors that can play a role in activation of the toxins. However, even this very critical element - the need for a specific receptor-is still disputed to some extent. For example, Gilliland et al. (2002) work with several Cryl toxins and find no correlation between its binding capacity and its potency (toxicity), saying "The correlation between binding and potency was inconsistent for the species-instar-toxin combinations used in this study, reaffirming the complex mode of action of Cry1 toxins." According to Pigott and Ellar (2007), most steps of toxin activation are still under discussion: "Even the general view that toxin monomers bind to midgut-receptors, oligomerize, and insert into the membrane to form lytic pores has recently been challenged." And Crickmore (2005) writes: "Nonetheless, convincing evidence now exists for the involvement of two proteins (cadherin and aminopeptidase $\mathrm{N}$ ) and a set of glycolipids as receptors of $\mathrm{Bt}$ toxins. Circumstantial evidence, based on binding studies, also exists for the involvement of many other membrane proteins. With so many potential binding sites, the question arises as to their relative importance."

The publications of Broderick et al. $(2006,2009)$ in particular reveal surprising results on the general mode of actions of Bt toxins. By showing that, in gipsy moth (Lymantria dispar), midgut bacteria are required to induce insecticidal activity in Cry1 $\mathrm{Ab}$ toxins (Broderick et al. 2006), the authors believe to describe a new general mechanism in activity of Bt toxins. As they point out: "For decades, the mechanism of insect killing has been assumed to be toxin-mediated lysis of the gut epithelial cells, which leads to starvation, or B.thuringiensis septicemia. Here, we report that $B$. thuringiensis does not kill larvae of the gypsy moth in the absence of indigenous midgut bacteria. Elimination of the gut microbial community by oral administration of antibiotics abolished $B$. thuringiensis insecticidal activity, and reestablishment of an Enterobacter sp. That normally resides in the midgut microbial community restored B.thuringiensis-mediated killing." In a later publication (Broderick et al. 2009), the published findings were more specific, based on comparison of six Lepidoptera species subjected to a treatment combining the application of antibiotics, Bt toxins, and certain gut bacteria. In most of the Lepidoptera species, the absence of gut bacteria led to a decrease of toxicity of the Bt toxins, while in one case, the opposite effect was observed. Boderick et al. (2009) also identified certain non-pathogenic gut bacteria from $L$. dispar being able to restore toxicity of $\mathrm{Bt}$ toxins if they are applied to insect larvae. They conclude that "perturbations caused by toxin feeding induce otherwise benign gut bacteria to exert pathogenic effects." Futhemore, Boderick et al. (2009) suggest that the mechanisms found "between B. thuringiensis and the gut microbiota of Lepidoptera may provide a useful model with which to identify the factors involved in such transitions." The authors think that their findings might be especially helpful in pest management by increasing susceptibility or preventing resistance. However, the authors do not consider any implications to risk assessment in non-target organism, but a detailed review of other publications reveals that additional factors are of general relevance of mechanism of Bt toxins. Some publications indicate that this is also relevant for susceptibility in non-target organisms.

According to Schnepf et al. (1998), there are reasons to assume that the broad range of naturally occurring toxins in B. thuringiensis can be explained to some extent by evolutionary principles, since coexpression of multiple toxins in general is likely to increase the host range. This assumption is supported not only by the great variety of different $\mathrm{Bt}$ toxins in bacterial strains but also by at least some evidence of a synergistic mode of action, as shown in some publications, revealing synergism (but also surprisingly antagonism) between the toxins as well as between the toxins and the spore part of the bacteria (Schnepf et al. 1998; Lee et al. 1996; Liu et al. 1998). Sharma et al. (2004) for example provide an overview of some publications that deal with the synergism (and sometimes antagonism) between different Cry1 toxins and between Cry1 and Cry2 toxins. Liu et al. (1998) show that synergism with the spore part can help to overcome resistance to the $\mathrm{Bt}$ toxin. Perez et al. (2005) describe synergism between Bt toxins that can help to replace the function of certain receptors.

Beyond that, Bt toxins not only show synergism with one another and the spore part of the bacteria but also with co-factors in their environment. For example, Sharma et al. 
(2004) also list several publications showing that enzymes and proteins from sources other than B. thuringiensis reveal relevant synergisms with Bt toxins. Dubois and Dean (1995) prove synergies with several bacteria, some of them related to infectious diseases. Koppenhöfer and Kaya (1997) identify interactions with further stress factors such as nematodes and cadmium in target organisms. Kramarz et al. (2007) show that additional factors such as cadmium and nematodes can enable $\mathrm{Bt}$ toxins to have an impact also on organisms such as snails (Helix aspersa), which do not show any effects on being exposed to the $\mathrm{Bt}$ toxin alone.

Altogether, several publications are available showing that the dose-response relationship can depend on synergism, very often resulting in a higher efficacy (toxicity) (Oppert 1999; Schnepf et al. 1998; Koppenhöfer and Kaya 1997; Kramarz et al. 2007; Sharma et al. 2004). Furthermore, in some cases, tendencies toward a change in specifity can be observed, leading to a lower selectivity (Schnepf et al. 1998; Kumar and Venkateswerlu 1998; Perez et al. 2005; Kramarz et al. 2007). These findings make it evident that the observed effects are relevant not only for target organisms but also for non-target organisms and therefore should be reflected in ecological risk assessment of $\mathrm{Bt}$ toxins. Selected publications with relevance for Cry1A toxins and potential factors enhancing toxicity are listed in Table 1 . This table shows not only few effects in non-target organism being found in this context, but it also shows that hardly any research was considered or performed on this specific topic. Figure 1 shows the steps necessary to activate Cry $1 \mathrm{Ab}$ and lists some factors that can have an impact on this process.

\section{Discussion}

Current genetic engineering in plants uses specific compounds derived from $B$. thuringiensis, which are supposed to have a high selectivity for some pest insects. For example, a modified Cry $1 \mathrm{Ab}$ is used quite frequently in crops such as maize MON810, Bt 11, and Bt 176. In some cases, the Bt toxins even get combined in the so-called stacked events containing more than one Bt toxin (see for example EFSA 2005). Risk assessment of Bt crops is largely based on the selectivity of the toxins used and the assumption of a linear dose-response relationship (Monsanto 2007). This approach seems to be too narrow, since, for example, the publications mentioned above show that the efficacy of Cry1 $\mathrm{Ab}$ can depend on additional factors (Dubois and Dean 1995; Schnepf et al. 1998; Sharma et al. 2004; Broderick et al. 2006; Li et al. 2007; Kramarz et al. 2007). As to the selectivity of Cry1 Ab and the question if it can be lowered by synergistic action, so far, no systematic research has been published, but there are some relevant scientific findings in non-target organisms supporting this thesis (Kaatz 2005; Kramarz et al. 2007). The investigation of Kaatz (2005), which so far is not available in peer reviewed publication, shows some interesting parallels with Broderick et al. $(2006,2009)$ and Dubois and Dean (1995): Honeybee colonies were found to be susceptible to Cry1 Ab if certain parasitic gut organism (Nosema apis) were apparent. Thus, this organism might act an additional stress factor, which enables some toxicity of Cry $1 \mathrm{Ab}$ in this specific non-target species. Even some experts who are convinced that there is but few evidence for the impact of $\mathrm{Bt}$ toxins on non-target organisms (and

Table 1 Examples for published research on factors influencing toxicity of Cry1A toxins

\begin{tabular}{|c|c|c|c|c|}
\hline Reference & Identified factors & $\begin{array}{l}\text { Effects on } \\
\text { efficacy }\end{array}$ & $\begin{array}{l}\text { Effects on } \\
\text { selectivity }\end{array}$ & $\begin{array}{l}\text { Relevance for non-target } \\
\text { organism discussed or } \\
\text { investigated }\end{array}$ \\
\hline Bravo et al. (2004) & Oligomerization by enzymes & + & $?$ & No \\
\hline Broderick et al. $(2006,2009)$ & Microorganism in the gut & + & $?$ & No \\
\hline Dubois and Dean (1995) & $\begin{array}{l}\text { Diverse bacteria } \\
\text { Bacterial spores }\end{array}$ & + & $?$ & No \\
\hline Gomez et al. (2002) & Oligomerization by antibodies and enzymes & + & $?$ & No \\
\hline Huang et al. (2002) & Activation of toxin by gene transfer to plants & + & $?$ & No \\
\hline Kaatz (2005) & Nosema apis (in honey bees) & + & + & Yes \\
\hline Kramarz et al. (2007) & Cadmium and nematodes (in snails) & + & + & Yes \\
\hline Lee et al. (1996) & Synergism with other Cry toxins & +- & $?$ & No \\
\hline Li et al. (2007) & Activation of toxin by gene transfer to plants & + & $?$ & No \\
\hline Soberon et al. (2007) & Oligomerization by genetic engineering & + & $?$ & No \\
\hline Sharma et al. (2004) & $\begin{array}{l}\text { Synergism with other Cry toxins } \\
\text { Protease inhibitors }\end{array}$ & +- & $?$ & No \\
\hline
\end{tabular}



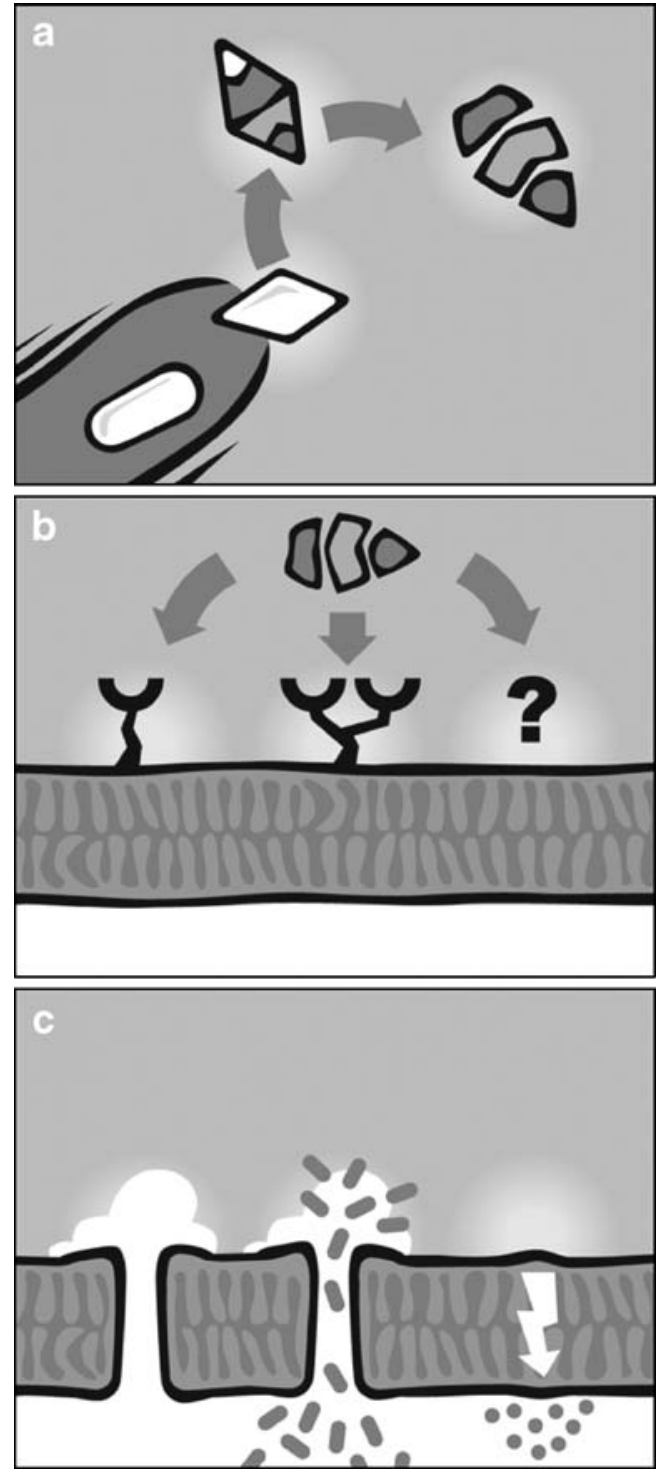

Fig. 1 Steps of activation of Cry toxins and some mechanisms contributing to its selectivity. a The crystal form of the protoxin is produced by Bacillus thuringiensis. It is transformed in the gut of the insect larvae to a solubilized active toxin, which is shorter than the protoxin and consists of three domains. An alkaline $\mathrm{pH}$ and certain enzymes are needed for this process of activation (Oppert 1999). These steps are not necessary for Cry toxins produced in genetically engineered plants, which are activated by the technical process and by plant enzymes (Hilbeck and Schmidt 2006; Li et al. 2007). b There is currently discussion on the relationships between several types of midgut receptors and the binding of the toxins, while some experts question the role of receptors in general (Crickmore 2005; Pigott and Ellar 2007). It is shown that some specific cofactors can synergize with the Cry toxins at this step (Perez et al. 2005; Soberon et al. 2007). It is not clear which role exactly extrinsic (stress) factors can play in this context. Synergies are observed by, for example, Dubois and Dean (1995), Kaatz (2005), and Kramarz et al. (2007), and several effects are reported on non-target organisms indicating need for further investigation. c Several mechanisms are discussed for the last step of toxin reaction: Models exist with and without pores in the epithelial cell layer and with and without involving gut bacteria (Broderick et al. 2006; Pigott and Ellar 2007) especially on honey bees) acknowledge that the potential synergism of Bt toxins with additional stress factors needs to be investigated further (Duan et al. 2008). This point of view is also shared by EFSA (2008).

In fact a broad range of publications can be identified, which deal with effects on non-target organism, but hardly, any explanatory mechanisms have been described so far. For example, several publications show effects of Cry $1 \mathrm{Ab}$ on insects not belonging to the group of Lepidoptera. Effects are described for Adalia bipunctata (Schmidt et al. 2008), Chrysoperla carnea (Hilbeck et al. 1998, 1999), Daphnia magna (Bøhn et al. 2008), Trichopteran, (Lepidostoma liba, Rosi-Marshall et al. 2007), honeybees (Apis mellifera, Ramirez-Romero et al. 2008), and others (see for example Lövei and Arpaia 2005).

Looking beyond insects, too, however, there are effects of Bt toxins that are difficult to explain by generally assumed receptor theories. According to Griffitts et al. (2005), only non-vertebrates can be seen as potential target organisms for Bt endotoxins. However, Huffmann et al. (2004) raise questions beyond receptor-specific activity of $\mathrm{Bt}$ toxins also being relevant for vertebrates. In addition, Ito et al. (2004) show cytocidal activity on human cells. Taking into accord the question of certain factors influencing the toxicity of Bt toxins in non-target organism such as mammals, it is interesting that Thomas and Ellar (1983) show that the effect of certain Bt toxins (from $B$. thuringiensis var. israelensis), which, in their native (crystallized) form, show no toxicity in mammalians, can become highly toxic in an alkali-solubilized form (if being administered parenteral).

There are several reasons for exploring this issue further especially in the context of genetically engineered plants. Compared to the naturally occurring (non-active) pro-toxin, the Bt toxin, as expressed in genetically engineered plants, not only has a different structure (Hilbeck and Schmidt 2006) but also has, partially, a changed quality in its mode of action. In addition, plant enzymes can help to activate (solubilize) the Bt toxin in MON810 (Li et al. 2007), so the resistance to native $\mathrm{Bt}$ toxins acquired in pest insects does not necessarily work on genetically engineered plants (Huang et al. 2002; Li et al. 2007). This finding is relevant for the issue of selectivity, since activation (solubilizing) normally requires certain conditions to be met in the gut of insects (de Maagd et al. 2001). As mentioned, Thomas and Ellar (1983) show that this step of activation can be decisive for toxicity of some Bt toxins (derived from $B$. thuringiensis var israelensis) on mammalian cells.

Also of relevance is the fact that the Bt toxin integrated into the genetically engineered plants is available throughout the whole season, and its concentration shows a broad range of variations (Nguyen and Jehle 2007; Then and Lorch 2008). This permanent exposure with varying 
concentrations leads to a higher probability of possible interactions with external factors.

\section{Conclusions}

In general, the mode of action of some Bt toxins might have been described well enough to explain how they work in target organisms. However, open questions still need to be answered, especially to which extent the selectivity and dose-response relationship of $\mathrm{Bt}$ toxins are influenced by synergism with certain extrinsic factors and if these effects could enable toxicity in non-target organisms. This review sees a risk assessment based only on the general assumption of high selectivity and a linear dose-response relationship as lacking a sufficient scientific basis. Thus, the issue of synergism, efficacy, and selectivity is a quite relevant topic for risk assessment of genetically engineered Bt crops.

\section{Recommendations and perspectives}

So far, there are no systematic (published) investigations related to risk assessment and synergism, selectivity, and efficacy of the Bt toxin in the context of risk assessment of genetically engineered crops. Most of the publications cited deal with emerging resistances in target organism and leave aside the issue of risk assessment in non-target organisms. There are several possibilities for further systemic investigation of impact of additional factors on the efficacy and selectivity of toxins that might be applied on Bt toxins, such as tests developed by Broderick et al. (2009) using the application of certain gut bacteria. Another test might be developed on the results of Kramarz et al. (2007), which studied the synergistic effects of abiotic and biotic stress factors on snails. Relevant models are also developed by pharmaceutical research (see for example Fang et al. 2008). Similar tests should be integrated in current risk assessment, also endorsing test systems such as mammalian cells, becoming a prerequisite for any market authorisation.

Acknowledgements This paper is part of a project on risk assessment of genetically engineered Bt plants funded by Greenpeace Germany. In the process of preparing the paper, 12 experts (some of them listed in the references) gave substantial input by answering a questionnaire. All the experts involved agreed that the questions raised in this review are relevant for risk assessment of Bt toxins and genetically engineered Bt plants.

Open Access This article is distributed under the terms of the Creative Commons Attribution Noncommercial License which permits any noncommercial use, distribution, and reproduction in any medium, provided the original author(s) and source are credited.

\section{References}

Bøhn T, Primicerio R, Hessen DO, Traavik T (2008) Reduced fitness of Daphnia magna fed a Bt-transgenic maize variety. Arch Environ Contam Toxicol 55(4):584-592

Bravo A, Gomez I, Conde J, Munoz-Garay C, Sanchez J, Miranda R, Zhuang M, Gill SS, Soberon M (2004) Oligomerzation triggers binding of a Bacillus thuringiensis Cry1 $\mathrm{Ab}$ pre-forming toxin to amninopeptidase $\mathrm{N}$ receptor leading to an insertion into mebrane microdomains. Biochim Biophys 1667:38-44

Broderick NA, Raffa KF, Handelsman J (2006) Midgut bacteria required for Bacillus thuringiensis insecticidal activity. PNAS 103(41):15196-15199

Broderick NA, Robinson CJ, McMahon MD, Holt J, Handelsman J, Raffa KF (2009) Contributions of gut bacteria to Bacillus turingiensis - induced mortality vary across a range of Lepidoptera. BMC Biol 7:11

Crickmore N (2005) Using worms to better understand how Bacillus thuringiensis kills insects. Trends Microbiol 13:347-350

de Maagd RA, Bravo A, Crickmore N (2001) How Bacillus thuringiensis has evolved specific toxins to colonize the insect world. Trends Genet 17:193-199

Duan JJ, Marvier M, Huesing J, Dively G, Huang ZY (2008) A metaanalysis of effects of $\mathrm{Bt}$ crops on honey bees (Hymenoptera: Apidae). PloS ONE 3(1):e1415

Dubois NR, Dean DH (1995) Synergismen between CrylA insecticidal crystal proteins and spores of Bacillus thuringiensis, other bacterial spores, and vegetative cells against Lymantria dispar (Lepidoptera: Lymantriidae) Larvae. Environ Entomol 24 (6): 1741-1747

EFSA (2005) Opinion of the European Food Safety Authority in accordance with Articles 6 and 18 of Regulation (EC) No 1829/ 2003 on application EFSA-GMO-DE-2004-03. http://www.efsa. europa.eu/EFSA/efsa locale-1178620753812 1178620784282. htm

EFSA (2008) Scientific opinion of the Panel on Genetically Modified Organisms on a request from the European Commission to review scientific studies related to the impact on the environment of the cultivation of maize Bt11 and 1507. EFSA J 851:1-27

Fang HB, Ross DD, Sausville E, Tan M (2008) Experimental design and interaction analysis of combination studies of drugs with loglinear dose responses. Stat Med 27:3071-3083

Gilliland A, Chambers CE, Bone EJ, Ellar DJ (2002) Role of Bacillus thuringiensis Cry1 endotoxin binding in determining potency during Lepidopteran larval development. Appl Environ Microbiol 68(4):1509-1515

Gomez I, Sanchez J, Miranda R, Bravo A, Soberon M (2002) Cadherin-like receptor binding facilitates proteolytic cleavage of helix æ-1 in domain I and oligomer per-pore formation of Bacillus thuringiensis Cry 1Ab toxin. FEBS Lett 513:242-246

Griffitts JS, Haslam SM, Yang T, Garczynski SF, Mulloy B, Morris H, Cremer PS, Dell A, Adang MJ, Aroian RV (2005) Glycolipids as receptors for Bacillus thuringienis crystal toxins. Science 307:922-925

Hilbeck A, Schmidt JEU (2006) Another view on Bt proteins-how specific are they and what else might they do? Biopesticides Int 2 (1): $1-50$

Hilbeck A, Moar WJ, Pusztai-Carey M, Filipini A, Bigler F (1998) Toxicity of Bacillus thuringiensis Cry1 Ab toxin to the predator Chrysoperla carnea (Neuroptera: Chrysopidae). Environ Entomol 27(5):1255-1263

Hilbeck A, Moar WJ, Pusztai-Carey M, Filipini A, Bigler F (1999) Prey-mediated effects of Cry1 Ab toxin and protoxin and Cry2A protoxin on the predator Chrysoperla carnea. Entomol Exp Appl 91:305-316 
Huang F, Buschman LL, Higgins RA, Li H (2002) Survival of Kansas dipel-resistant European corn borer (Lepidoptera: Crambidae) on Bt and Non-Bt corn hybrids. J Econ Entomol 95:614-621

Huffmann DL, Abrami L, Sasik R, Corbeil J, van der Goot G, Aroian RV (2004) Mitogen-activated protein kinase pathways defend against bacterial pore-forming toxins. Proc Natl Acad Sci U S A 101:10995-11000

ISAAA (2009) Executive Summary Global Status of Commercialized Biotech/GM Crops: 2008. http://www.isaaa.org/resources/ publications/briefs/39/executivesummary/default.html

Ito A, Sasaguri Y, Kitada S, Kusaka Y, Kuwano K, Masutomi K, Mizuki E, Akao T, Ohba M (2004) Bacillus thuringiensis crystal protein with selective cytocidal action on human cells. J Biol Chem 279:21282-21286

Jimenez-Juarez N, Munoz-Garay C, Gomez I, Saab-Rincon G, Gill Damian-Almazo JY, SS SM, Bravo A (2007) Bacillus thuringiensis Cry1 $\mathrm{Ab}$ Mutants affecting oligomer formation are non-toxic to Manduca sexta larvae. J Biol Chem 282 (29):21222-21229

Kaatz HH (2005) Auswirkungen von Bt- Maispollen auf die Honigbiene, Uni Jena, Sicherheitsforschung und Monitoring zum Anbau von Bt-Mais. http://www.biosicherheit.de/de/ sicherheitsfo rschung/68.doku.html

Koppenhöfer AM, Kaya HK (1997) Additive and synergistic interaction between entomophatogenic nematodes and Bacillus thuringiensis for scarab grub control. Biol Control 8:131-137

Kramarz PE, Vaufleury A, Zygmunt PMS, Verdun C (2007) Increased response to cadmium and bacillus thuringiensis maize toxicity in the snail Helix aspersa infected by the nematode Phasmarhabditis hermaphrodita. Environ Toxicol Chem 26(1):73-79

Kumar AS, Venkateswerlu G (1998) Endogenous protease-activated 66-kDa toxin from Bacillus thuringiensis subsp. kurstaki active against Spodoptera littoralis. FEMS Microbiol Lett 159:113-120

Lee MK, Curtiss A, Alcantara E, Dean DH (1996) Synergistic effect of the Bacillus thuringiensis toxins CryIAa and CryIAc on the Gypsy Moth, Lymantria dispar. Appl Environ Microbiol 62 (2):583-586

Li H, Buschman LL, Huang F, Zhu KY, Bonning B, Oppert BA (2007) Resistance to Bacillus thuringiensis endotoxins in the European corn borer. Biopestic Int 3(2):96-107

Liu YB, Tabashnik BE, Moar WJ, Smith RA (1998) Synergism between Bacillus thuringiensis spores and toxins against resistant and susceptible Diamondback Moths (Plutella xylostella). App Environ Microbiol 64(4):1385-1389

Lövei GL, Arpaia S (2005) The impact of transgenic plants on natural enemies: a critical review of laboratory studies. Entomol Exp Appl 114:1-14

Monsanto (2007) Application for renewal of the authorisation for continued marketing of existing MON 810 maize products that were authorized under Directive 90/220/EEC (Decision 98/294/ EC) and subsequently notified in accordance to Article 20(1)(a) of Regulation (EC) No 1829/2003 on genetically modified food and feed, Part II, Summary, 7.8:16
Nguyen HT, Jehle JA (2007) Quantitative analysis of the seasonal and tissue-specific expression of CrylAb in transgenic maize Mon810. J Plant Disease Protect 114(2):82-87

Oppert B (1999) Protease interactions with Bacillus thuringiensis insecticidal toxins. Arch Insect Biochem Physiol 42:1-12

Perez C, Fernandez LE, Sun J, Folch JL, Gill SS, Soberon M, Bravo A (2005) Bacillus thuringiensis subsp. israelensis Cyt1Aa synergizes Cry11Aa toxin by functioning as a membrane-bound receptor. Proc Natl Acad Sci U S A 102(51):18303-18308

Pigott CR, Ellar DJ (2007) Role of receptors in Bacillus thuringiensis crystal toxin activity. Microbiol Mol Biol Rev 71(2):255-281

Ramirez-Romero R, Desneux N, Decourtyec A, Chaffiol A, PhamDelegue MH (2008) Does Cry1Ab protein affect learning performances of the honey bee Apis mellifera L. (Hymenoptera, Apidae)? Ecotoxicol Environ Saf. 70:327-333. doi:10.1016/j. ecoenv.2007.12.00

Rosi-Marshall EJ, Tank JL, Royer TV, Whiles MR, Evans-White M, Chambers C, Griffiths NA, Pokelsek J, Stephen ML (2007) Toxins in transgenic crop by-products may affect headwater stream ecosystems. Proc Natl Acad Sci U S A 104:16204-16208

Schmidt JEU, Braun CU, Whitehouse LP, Hilbeck A (2008) Effects of activated $\mathrm{Bt}$ transgene products (Cry $1 \mathrm{Ab}, \mathrm{Cry} 3 \mathrm{Bb})$ on immature stages of the ladybird Adalia bipunctata in laboratory ecotoxicity testing. Arch Environ Contam Toxicol . doi:10.1007/s00244-0089191-9

Schnepf E, Crickmore N, van Rie J, Lereclus D, Baum J, Feitelson J, Zeigler DR, Dean DH (1998) Bacillus thuringiensis and its pesticidal crystal proteins. Microbiol Mol Biol Rev 62(3):775-806

Sharma HC, Sharma JH, Crouch KK (2004) Genetic transformation of crops for insect resistance: potential and limitations. Crit Rev Plant Sci 23:47-72

Soberon M, Pardo-Lopez L, Lopez I, Gomez I, Tabashnik BE, Bravo A (2007) Engineering modified Bt toxins to counter insect resistance. Science 318:1640-1642

Then C, Lorch A (2008) A simple question in a complex environment: how much $\mathrm{Bt}$ toxin do genetically engineered MON810 maize plants actually produce? In: Breckling B, Reuter H, Verhoeven R (eds) Implications of GM-crop cultivation at large spatial scales. Theorie in der Ökologie 14. Frankfurt, Peter Lang. http://www. gmls.eu/index.php?contact=ja

Thomas WE, Ellar DJ (1983) Bacillus thuringiensis var israelensis crystal delta-endotoxin: effects on insect and mammalian cells in vitro and in vivo. J Cell Sci 60(1):181-197

Tilley SJ, Saibil HR (2006) The mechanism of pore formation by bacterial toxins. Curr Opin Struct Biol 16:230-236

Zhang X, Candas M, Griko NB, Rose-Young L, Bulla LA Jr (2005) Cytotoxicity of Bacillus thuringiensis Cryl Ab toxin depends on specific binding of the toxin to the cadherin receptor BT-R1 expressed in insect cellls. Cell Death Differ 12:1407-1416

Zhang X, Candas M, Griko NB, Rose-Young L, Bulla LA Jr (2006) A mechanism of cell death involving an adenylyl cyclase/PKA signaling pathway is induced by the Cry1 Ab toxin of Bacillus thuringiensis. Proc Nat Acad Sci U S A 103:9897-9902 